\title{
An international analysis of cigarette affordability
}

\author{
E H Blecher, C P van Walbeek
}

Tobacco Control 2004;13:339-346. doi: 10.1136/tc.2003.006726

\begin{abstract}
Objective: To investigate how affordable cigarettes are in developed and developing countries, and to calculate by how much the affordability of cigarettes has changed between 1990 and 2001; and secondly, to investigate the relation between cigarette affordability and consumption.

Design: Affordability was defined as the cost of cigarettes relative to per capita income. Trends in cigarette affordability, and affordability elasticities of demand, were estimated using regression techniques.

Subjects: Seventy countries were investigated, of which 28 are categorised as high income developed countries, while 42 are categorised as developing countries. Cigarette prices were obtained for the main city/cities in the countries.

Results: Despite the fact that cigarettes are more expensive in developed countries, the high levels of

income make cigarettes more affordable in these countries vis-à-vis developing countries. Of the 28

developed countries, cigarettes became more affordable in 11 and less affordable in 17 countries during the 1990s. Of the 42 developing countries, cigarettes became more affordable in 24 and less affordable in 18 countries. Based on a cross sectional analysis, a $1 \%$ increase in the relative income price (the inverse of cigarette affordability) is expected to decrease cigarette consumption by between $0.49-0.57 \%$.

Conclusions: Cigarette affordability, more than just the price, determines cigarette consumption. While cigarettes have become more affordable in many developing countries, some developing countries (for example, South Africa, Poland, and Thailand) have implemented strong and effective tobacco control policies, and have been able to decrease cigarette consumption as a result.
\end{abstract}

See end of article for authors' affiliations

Correspondence to:

Mr Corné P van Walbeek,

School of Economics,

University of Cape Town,

Cape Town 7701, South

Africa; cwalbeek@

commerce.uct.ac.za

Received

18 November 2003

Accepted 23 June 2004

$\mathrm{T}$ here is consensus among tobacco control economists that tobacco excise tax increases are an extremely effective way of reducing tobacco consumption. ${ }^{12}$ An increase in the tobacco tax increases the retail price of tobacco products, which in turn decreases consumption. Despite the addictiveness of tobacco, econometric studies have shown that a $10 \%$ increase in the real (that is, inflation adjusted) price of cigarettes reduces cigarette consumption by about $4 \%$ in high income countries and by between $4-8 \%$ in low and middle income countries. ${ }^{3} 4$

Affordability usually refers to the ability of an individual to purchase a product. This is influenced by the price of the product and the individual's income. In this paper, affordability is defined as the price of the product, relative to the income of the (potential) consumer. In low income countries cigarettes are often less affordable, even though they are generally cheaper in absolute terms, than in high income countries. Most economic studies on the determinants of demand for cigarettes focus on the (real) price of cigarettes. ${ }^{24}$ The aim of this paper is to consider explicitly the rather neglected aspect of cigarette affordability in a sample of high income and low and middle income countries. ${ }^{* 5}$ Also, we investigate the relation between cigarette consumption and affordability.

\section{CIGARETTE PRICES AND AFFORDABILITY}

If one were to express the price of cigarettes in a common currency (the US dollar), one would notice large differences between countries. Depending on one's country of origin, cigarettes are expensive in countries such as Australia, the UK, and the Scandinavian countries, while they are cheap in countries such as Brazil, Pakistan, and Kenya. ${ }^{36}$ As a general principle, when expressed in a common currency, cigarette

\footnotetext{
*According to the World Bank, countries are classified as high, upper middle, lower middle, or low income countries. In this paper the term middle income countries refers to both upper and lower middle income
} countries.

prices are usually much higher in high income countries than in low and middle income countries.

Does that imply that cigarettes are more affordable in high income countries, vis-à-vis low and middle income countries? Not necessarily, for two reasons. Firstly, the ruling exchange rate may not accurately reflect the purchasing power of different currencies. For example, the local currency equivalent of UK $£ 100$ (converted at the ruling exchange rate) will command a much larger basket of goods and services in South Africa than in the UK. In 2003 the local currency equivalent price of a pack of cigarettes in South Africa was about US\$1.60, compared to a local currency equivalent price in excess of US\$6 in the UK. At first sight cigarette prices are about four times higher in the UK than in South Africa, but this is misleading as a measure of cigarette affordability because practically all things are more expensive in the UK than in South Africa, when expressed in a common currency unit. Thus, before making any comparisons between prices of cigarettes in different countries, one has to adjust for differences in the purchasing power of the currencies involved.

Secondly, standards of living vary immensely between countries. Even if the impact of differences in price levels between countries is removed, the average per capita income in high income countries is more than 10 times the average income in low income countries. ${ }^{5}$ Thus, a pack of cigarettes that costs the equivalent of US\$3 is much more affordable in the US than in Kenya, even if one accounts for differences in the price level, simply because the standard of living is so much higher in the USA.

Recently, a number of papers that investigated the affordability of cigarettes were published in Tobacco Control. Using the Big Mac index as the basis of comparison, Scollo ${ }^{7}$ and Lal and Scollo ${ }^{8}$ calculated the "relative price" of cigarettes in terms of Big Mac hamburgers. The Big Mac

Abbreviations: EIU, Economist Intelligence Unit; GDP, gross domestic product; RIP, relative income price; UBS, Union Bank of Switzerland 


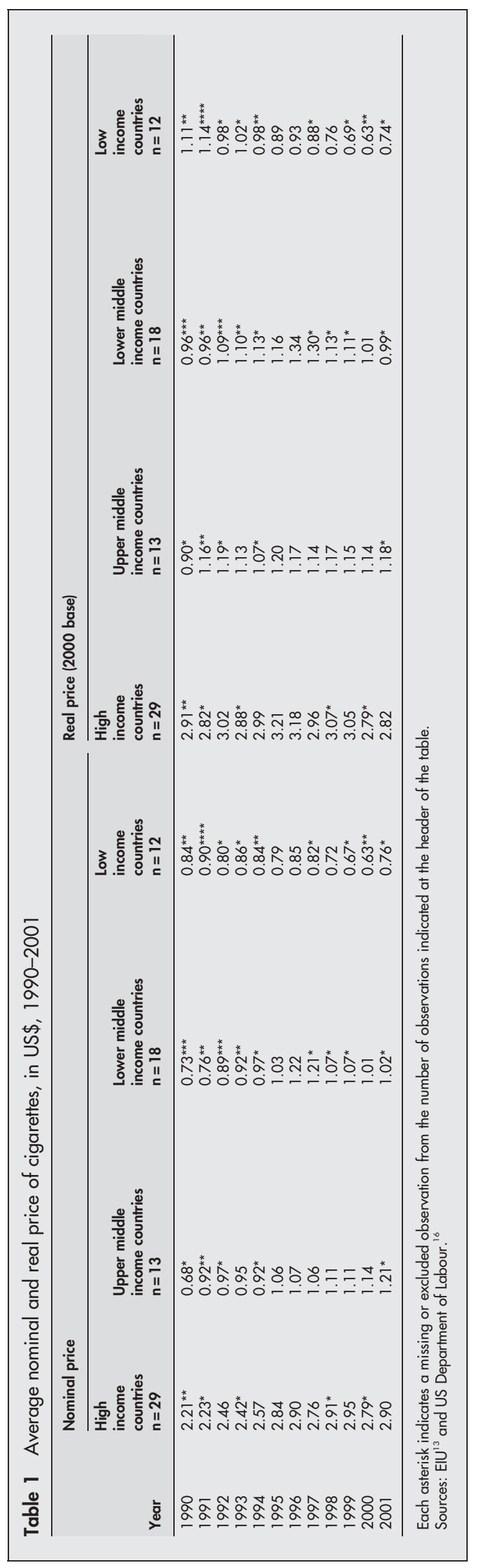

hamburger standard was created by The Economist magazine in 1986 as a light hearted approach to determine the magnitude of the deviation from purchasing power parity exchange rates and to predict the direction of change in the exchange rate. ${ }^{9} 10$

A comparison of the two studies by Scollo reveals that between 1996 and 2002 the relative price of cigarettes, expressed in Big Mac terms, has increased in 15 of the 16 countries that were included in both surveys. From a tobacco control perspective, this is a most encouraging finding. Taiwan was the only country where the relative price of cigarettes decreased. However, these studies cannot be used to draw conclusions about cigarette price trends in poorer countries, since the common sample is limited nearly exclusively to high income countries. Also, the Scollo studies only investigate differences in relative prices between countries, not the affordability of cigarettes. To measure changes in affordability, one has to account for differences in income levels between countries, which, as has been pointed out, differ widely between countries.

In order to create a more realistic measure of affordability of cigarettes, Guindon et $\mathrm{al}^{11}$ calculated the average number of working minutes required to buy a pack of local brand or Marlboro (or equivalent) cigarettes, based on the Union Bank of Switzerland (UBS) survey of prices and earnings. ${ }^{12}$ The wage was based on the net hourly wage in 12 occupations. $^{\dagger}$ They found that in 10 of the 36 countries surveyed, cigarettes became more affordable between 1990 and 2000. ${ }^{\ddagger}$ Within this sample of countries, cigarettes became more affordable in six of the $25(24 \%)$ high income countries and in four of the 11 $(36 \%)$ of the low and middle income countries.

For any individual country, tobacco control policy correctly focuses on the impact that changes in the price and/or affordability of cigarettes will have on cigarette consumption. People change their smoking behaviour, not because cigarettes are expensive or cheap, but because cigarettes are becoming more or less expensive. Guindon et al also focus on the aspect of changes in affordability, and on the basis of their analysis argue that there is ample room to increase tobacco taxes. ${ }^{11}$

Can the concept of cigarette affordability help us to explain why cigarette consumption is high in some countries and low in others? Intuitively one would expect countries where cigarettes are more affordable to have higher levels of cigarette consumption than countries where cigarettes are less affordable. This aspect was not considered in the Guindon study, but is an important element of this paper.

\section{SOURCES AND METHODS}

Information on cigarette prices was sourced from The Economist Intelligence Unit's (EIU) World Cost of Living Survey. ${ }^{13}$ This survey is conducted semi-annually in order to assess the prices of goods in more than 130 of the world's major cities in nearly 90 countries. The prices used in this study were collected in the first week of September, and covers each year for the period 1990 to 2001 .

The survey considers the prices of two cigarette brands (Marlboro or the nearest international equivalent, and a local brand) sold at two types of outlet (high volume supermarket,

†Gross wages are adjusted for differences in working time, holidays and vacations. The 12 occupations are primary school teachers, bus drivers, automobile mechanics, building labourers, skilled industrial workers, cooks, department managers, electrical or mechanical engineers, bank credit clerks, secretaries, saleswomen, and female industrial workers.

$\ddagger$ These countries are Austria (increase in affordability of Marlboro only), Canada, Denmark, India, Japan, Malaysia, the Philippines, Portugal',
Sweden, and Taiwan. 
Table 2 Average percentage of per capita GDP required to purchase 100 packs of cigarettes, 1990 to 2001

\begin{tabular}{lllll}
\hline & $\begin{array}{l}\text { High } \\
\text { income } \\
\text { countries } \\
\mathbf{n = 2 9}\end{array}$ & $\begin{array}{l}\text { Upper middle } \\
\text { income countries } \\
\mathbf{n = 1 3}\end{array}$ & $\begin{array}{l}\text { Lower middle } \\
\text { income countries } \\
\mathbf{n = 1 8}\end{array}$ & $\begin{array}{l}\text { Low } \\
\text { income } \\
\text { countries } \\
\mathbf{n}=12\end{array}$ \\
\hline 1990 & $1.21^{* *}$ & $2.49^{*}$ & $8.32^{* * *}$ & $17.83^{* *}$ \\
1991 & $1.28^{*}$ & $2.70^{* *}$ & $6.72^{* *}$ & $16.61^{* * * *}$ \\
1992 & 1.30 & $2.55^{*}$ & $7.18^{* * *}$ & $15.69^{*}$ \\
1993 & $1.31^{*}$ & 2.46 & $8.68^{* *}$ & $19.27^{*}$ \\
1994 & 1.31 & $2.27^{*}$ & $7.95^{*}$ & $17.45^{* *}$ \\
1995 & 1.26 & 2.44 & 7.71 & 16.74 \\
1996 & 1.25 & 2.34 & 8.02 & 15.96 \\
1997 & 1.23 & 2.15 & $7.94^{*}$ & $16.92^{*}$ \\
1998 & $1.31^{*}$ & 2.31 & $7.22^{*}$ & 15.77 \\
1999 & 1.35 & 2.31 & $7.48^{*}$ & $15.37^{*}$ \\
2000 & $1.28^{*}$ & 2.27 & 6.80 & $13.63^{* *}$ \\
2001 & 1.37 & $2.45^{*}$ & $6.90^{*}$ & $16.94^{*}$ \\
\hline Each asterisk indicates a missing or excluded observation from the number of observations indicated at the header \\
of the table. \\
Sources: ElU' ${ }^{13}$ and World Bank. ${ }^{14}$ & & &
\end{tabular}

and mid-price retail outlet). ${ }^{\S}$ Since the emphasis of this study is on affordability, the lowest of the four prices (that is, the two brands in the two types of outlet) in each year was selected. For countries with more than one city included in the survey, an average price was calculated, each city being weighed equally.

Gross domestic product (GDP) per capita, expressed in US dollars, was used as the indicator of income. ${ }^{14}$ The advantage of this measure is that it is calculated annually using a consistent methodology and, despite the drawback that it does not take differences in the distribution of income into account, is generally regarded as a good indicator of living standards. In contrast to the present study, Guindon et al ${ }^{11}$ used the weighted average wage of 12 occupations as their measure of income. ${ }^{12}$ While this is a more direct way of estimating people's income, the drawback is that the UBS survey on earnings is performed only every three years and covers a much smaller sample of cities than the EIU survey on cigarette prices.

In this paper we define cigarette affordability as the percentage of per capita GDP required to buy 100 packs of cigarettes. For lack of a better term, the resulting percentage is called the relative income price (RIP). Of course, the higher the RIP, the less affordable cigarettes are, and vice versa.

The RIP was calculated for each country and each year for the period 1990 to 2001. The selection of countries was determined solely by data availability. For some years the RIP was not calculated, either as a result of data unavailability or because of a conscious decision to exclude observations that seemed obviously incorrect. ${ }^{* *}$

The typical way to determine whether cigarettes have become more or less affordable in the 11 years since 1990 would be to compare the 2001 to the 1990 value. If no information on cigarette prices is available for the period between the starting and ending years, this is the appropriate procedure. However, it is quite conceivable that the starting or ending value is an outlier-that is, significantly above or

§The price data used is from the same source as used by Guindon et al. The EIU collects data from three sources although only two were provided by them and thus the third source is not used in this study.

**Some judgment, rather than a fixed rule, was applied here. As a general principle, if the RIP changed by more than $40 \%$ from one year to the next, and this was not the start of a new price trend (which would presumably be the result of a conscious tobacco control strategy), the observation was ignored. The full dataset, including the values that have been excluded from the subsequent analysis, is available at (http://www.commerce.uct.ac.za/Economics/staff/cwalbeek/Documents/ blecher_and_van_wallbeek_2004.xls) below the underlying trend. In such a case, the calculated growth rate will be unrepresentative of the true trend. To prevent such distortions, a constant growth regression line ${ }^{15}$ was fitted on all observations. ${ }^{\dagger \dagger}$

Growth rates in the RIP were calculated for 70 countries. The World Bank's classification ${ }^{5}$ was used to divide the countries into four income categories: high income (28 countries), higher middle income (13 countries), lower middle income (18 countries), and low income (11 countries). Low and middle income countries have been given greater exposure in this analysis relative to the studies by Scollo ${ }^{78}$ and Guindon et al. ${ }^{11}$

Data on cigarette consumption were obtained for the period 1990 through 2000 from Shafey et al. ${ }^{6}$ Cigarette consumption was defined as the average number of cigarettes smoked by people aged 15 and older. Unfortunately, the consumption data are less complete than the affordability data, with observations missing at times. A detailed discussion of the methodology and limitations of the consumption data is available in Shafey et al. ${ }^{6}$

\section{RESULTS}

Table 1 displays trends in the average nominal price and real price of cigarettes, converted to US dollars at the prevailing exchange rate, for the four categories of countries. In this table the prices have not been adjusted for differences in purchasing power and/or income levels. This table clearly illustrates the well known fact that cigarette prices are much higher in high income countries, vis-à-vis low and middle income countries. Despite some important tobacco control interventions in many high income and some low and middle income countries, cigarette prices, on average, have not increased significantly during the 1990s. The (unweighted) average nominal price of cigarettes has been increasing at an average annual rate of $2.6 \%$ in high income countries, compared to $3.6 \%$ in upper middle income countries, and $3.2 \%$ in lower middle income countries. In low income countries the nominal price of cigarettes has decreased on average by $2.3 \%$ per year. The (unweighted) average real price of cigarettes has, on average, shown no change in high income countries, compared to a $1.0 \%$ average annual increase in upper middle income countries, and a $0.6 \%$ increase in lower middle income countries. In low income

$\dagger+$ This entails fitting the following regression line: $\ln \left(R P_{t}\right)=\alpha+\beta t+e_{t}$ where $t=0,1,2, \ldots$ The estimated value of $\beta$ is the weighted constant growth rate of the RIP. 


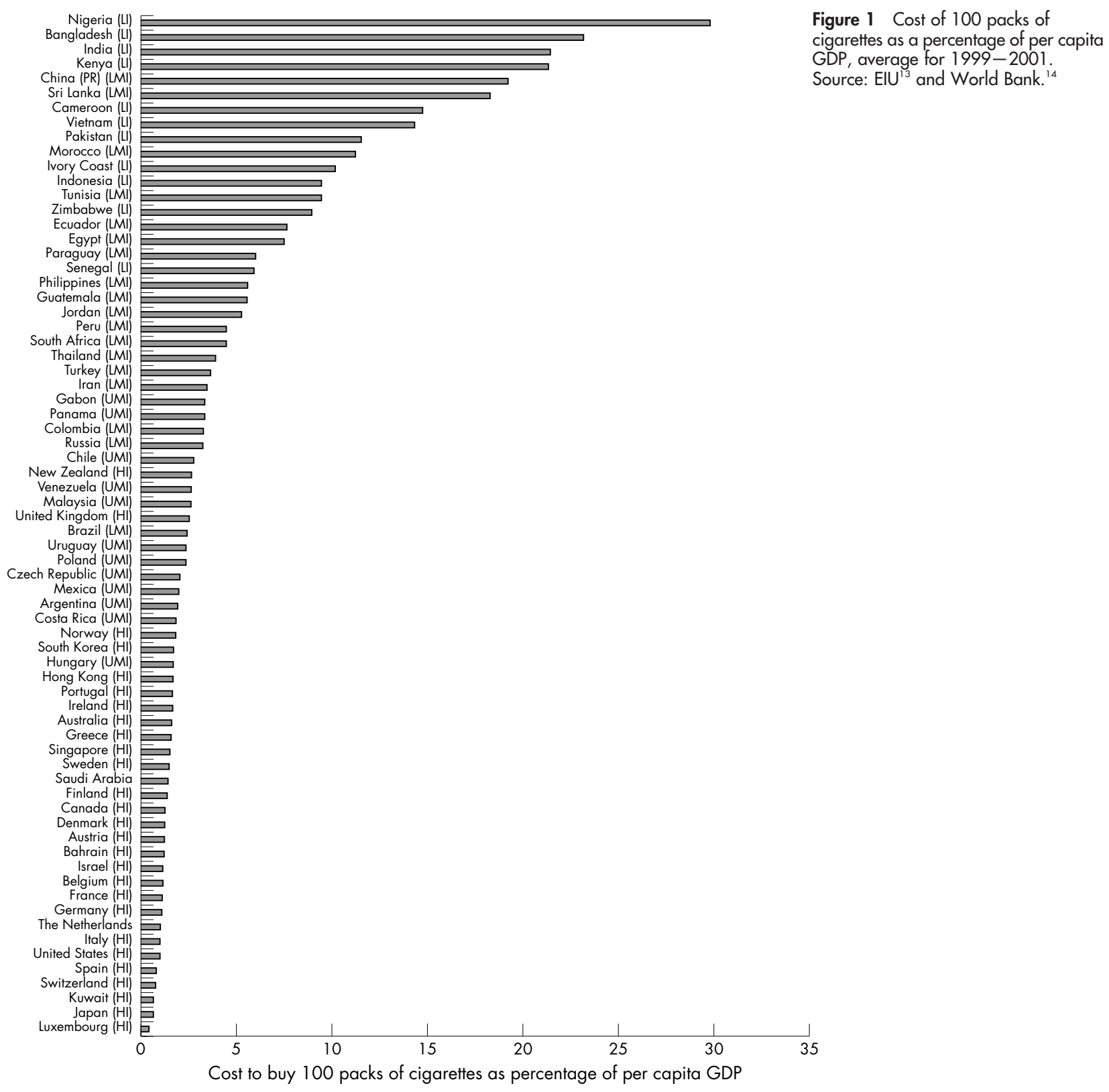

countries the real price of cigarettes has decreased on average by $4.9 \%$ per year.

While table 1 is potentially useful to smokers who travel abroad and may want to buy cheaper cigarettes in low and middle income countries, it does not say much about the affordability of cigarettes to local consumers. The affordability of cigarettes, defined as the percentage of per capita GDP required to buy 100 packs of cigarettes (that is, the RIP), is shown in table 2 for the four categories of countries.

Despite the fact that cigarettes are more expensive in high income countries, they are much more affordable to the average citizen than in the developing world. In fact, using this measure of affordability, cigarettes are about two times more affordable in high income countries than in upper middle income countries, nearly six times more affordable than in lower middle income countries, and more than 12 times more affordable than in low income countries.

Figure 1 shows the average RIP for the period 1999 to 2001 for all countries for which data are available. The very large spread in the RIPs is immediately apparent, with cigarettes, predictably, being least affordable in low income countries and most affordable in high income countries. According to this measure of affordability, cigarettes are 68 times more affordable in Luxembourg (with high average incomes) than in Nigeria (whose per capita income, adjusted for changes in purchasing power, is less than $2 \%$ that of Luxembourg's). The two high income countries with the least affordable cigarettes are the UK and New Zealand.

In fig 2 the average annual change in the RIP is shown for 70 countries. Between 1990 and 2001 the RIP of cigarettes increased in precisely half of these countries, while it decreased in the other half. Of the 28 high income countries, the RIP increased in 17 countries, and decreased in 11 , suggesting that cigarettes have, on average, become slightly less affordable in high income countries. Of the 13 upper middle income countries in the sample, the RIP increased in seven and decreased in six. Of the 18 lower middle income countries, the RIP has increased in six and decreased in 12 , suggesting that cigarettes have, on average, become more affordable in this group of countries. For the 11 low income 


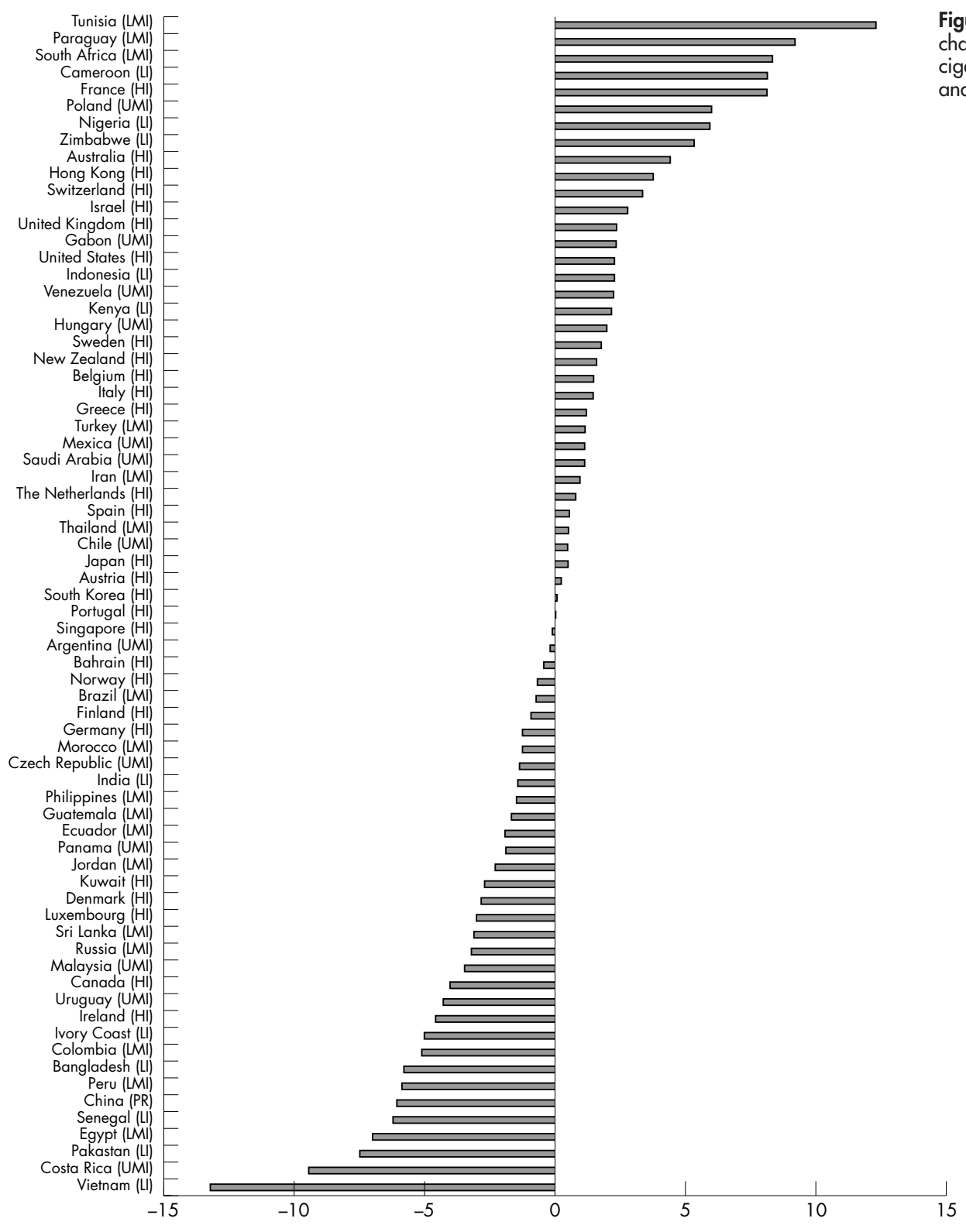

Figure 2 Average annual percentage change in the relative income price of cigarettes, 1990 to 2001 . Source: $\mathrm{ElU}^{13}$ and World Bank. ${ }^{14}$

countries in the sample, the RIP has increased in five and decreased in six countries.

While it would be fair to say that, generally, cigarettes have become slightly less affordable in high income countries, and slightly more affordable in low and middle income countries, the data do not allow one to make any strong generalisations. In some developing countries, notably Vietnam, Costa Rica, Egypt, Pakistan, Senegal, and China, the RIP of cigarettes has decreased by more than $50 \%$ during the 1990s. On the other hand, the largest increases in the RIP of cigarettes have also been in low and middle income countries: Tunisia, Paraguay, South Africa, and Cameroon. Changes in the affordability of cigarettes, both upwards and downwards, have generally been more modest in high income countries.

For countries that have experienced a rapid decrease in the RIP (that is, increasing cigarette affordability) this is usually the result of either high overall inflation or high economic growth (for example, China). No high income countries fall into this category. For countries that have experienced a rapid increase in the RIP (that is, decreasing cigarette affordability) the result is usually due to a focused tobacco control policy, where rapid tax increases formed the core of such a policy (for example, South Africa and Poland). While some high income countries have increased tobacco taxes sharply during the 1990s (for example, Australia, Hong Kong, Switzerland, and the UK) the increases came off a much higher base value than these low and middle income countries, where tobacco control was often completely ignored during the 1980s and before.

According to the law of demand, people will generally demand more of a product as the price decreases. Keeping other factors (like incomes, the prices of other goods and services, and people's tastes) constant, a decrease in the price makes the product more affordable. In the context of this study, one would expect per capita consumption of cigarettes to be higher in countries where cigarettes are more affordable than in countries where they are less affordable. Of specific interest would be, firstly, the strength of the relation, and secondly, the magnitude of the relation-that is, by how much per capita cigarette consumption is likely to differ, for every $1 \%$ difference in the affordability of cigarettes.

In fig 3 the RIP of cigarettes is plotted against per capita cigarette consumption for the first, middle, and last years for 


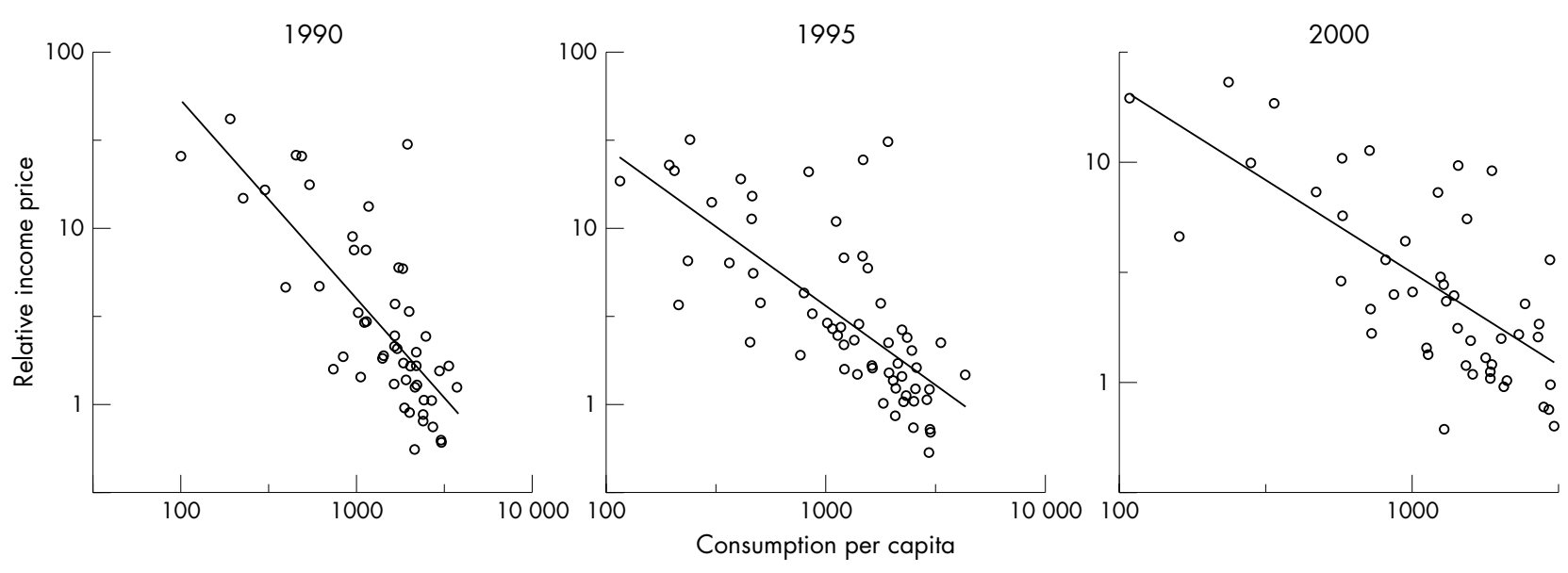

Figure 3 Relation between cigarette consumption and the relative income price. Source: EIU ${ }^{13}$ and Shafey et al. ${ }^{6}$

which the consumption data are available: 1990, 1995, and 2000. The figure reveals a consistent and strong relation $(r=-0.58, r=-0.51$, and $r=-0.52$ for the three years, respectively) between cigarette affordability and consumption, as is predicted by the law of demand.

To quantify the magnitude of the relationship between cigarette affordability and consumption, the following regression equation was specified:

$\ln \left(\right.$ cons $\left._{\mathrm{it}}\right)=\alpha_{1}+\alpha_{2} \ln \left(\mathrm{RIP}_{\mathrm{it}}\right)+\epsilon_{\mathrm{it}}$

where cons $\mathrm{it}_{\mathrm{it}}=$ per capita cigarette consumption in country $\mathrm{i}$ in period $\mathrm{t}$; $\mathrm{RIP}_{\mathrm{it}}=$ relative income price in country $\mathrm{i}$ in period $\mathrm{t}$; and $\epsilon_{\mathrm{it}}=$ the error term.

The results were based on a pooled data set of 72 countries and 11 years. ${ }^{\ddagger \neq}$ of the potential sample size of 792 observations, 580 were included in the regression, the others being excluded on the grounds that the data were either unavailable or unbelievable. Using ordinary least squares, the value of $\alpha_{2}$ is estimated at -0.530 (95\% confidence interval (CI) -0.574 to $-0.486 ; R^{2}=0.490$ ). This is interpreted as the affordability elasticity of demand. It indicates that for every $10 \%$ difference in the affordability of cigarettes between countries, cigarette consumption is likely to differ by $5.3 \%$. The magnitude of the affordability elasticity is very similar to the price elasticities of demand that have been estimated for many countries. ${ }^{4}$

Using this econometric model, possible differences in the magnitudes of the affordability elasticities between high income countries on the one hand, and low and middle income countries on the other, were investigated. In contrast to the findings that the absolute value of the price elasticity of demand is generally higher for lower income countries, ${ }^{2}$ the affordability elasticity of demand did not differ significantly between rich and poor countries. Also, no evidence was found that the affordability elasticity of demand has changed over time.

\section{DISCUSSION}

\section{Affordability, not only price, is important}

Even though the price of cigarettes, expressed in a common currency, is much higher in high income countries, cigarettes are much more affordable in these countries than in low and

‡¥Two countries, Papua New Guinea and the United Arab Emirates, are included in this analysis, even though they were excluded in the analysis presented in fig 1 and 2 . The reason for their exclusion in earlier analysis is because data did not exist for the period 1999 through 2001. They are included here, because earlier data are available. middle income countries. The reason is that the relative difference in average income levels between high income and low and middle income countries is larger than the relative difference in cigarette prices.

Since cigarette affordability is defined as the cost of cigarettes relative to income, changes in cigarette affordability are determined by changes in cigarette prices and changes in income. At the very least, taxes should be adjusted to maintain the real price of cigarette-that is, the price of cigarettes relative to the average price level in the economy. However, even if the real price of cigarettes stays constant, cigarettes become more affordable if the economy is growing rapidly, and per capita income is rising. For example, during the 1990s cigarettes became much more affordable in China, not because the price of cigarettes was decreasing, but because average income levels were increasing more rapidly than the increase in cigarette prices.

The implication is that governments, who are serious about tobacco control, should adjust the excise tax on cigarettes not only to maintain the real price of cigarettes, but also to prevent cigarettes from becoming more affordable over time. To keep the affordability of cigarettes at the same level from year to year, the price would have to increase by the inflation rate plus the rate of real per capita income growth in the economy.

\section{Cigarette affordability and consumption}

As previously pointed out, numerous econometric studies have investigated the price elasticity of demand, and have found that the price elasticity is around -0.4 for high income countries and between -0.4 and -0.8 for low and middle income countries. Until recently most of these estimates were based on time series data for individual countries. ${ }^{4}$ However, since 1998 a large number of studies have investigated price and income elasticities of demand based on household surveys. Guindon et al, in a review of such studies in low and middle income countries, show that the price elasticity of demand for lower income households tends to be higher in absolute terms than higher income households, and thus that the poor change their cigarette consumption more in response to a price change than the rich. ${ }^{17}$

In this paper we extended the principle of price elasticity to an affordability elasticity of demand. The value of the affordability elasticity was estimated at -0.53 , suggesting that for every $10 \%$ increase in the RIP (and thus an equivalent decrease in the affordability of cigarettes) per capita cigarette consumption is likely to decrease by $5.3 \%$. This result is consistent with the many studies that 
investigate the demand for cigarettes, namely that a given increase in the real price (which reduces the affordability of the product) reduces the quantity of cigarettes demanded, but by a somewhat smaller percentage. However, the elegance of this conclusion lies in the fact that it is based on a different research methodology (that is, using the concept of cigarette affordability, rather than price) and using different type of data (that is, panel data, rather than time series data). The present study thus reconfirms the well researched conclusion that a tax induced increase in the real price of cigarettes is a very effective method of reducing cigarette consumption.

The results of this study are limited by the complexities of working with cross country data. As such we were limited to using GDP as a measure of income and of the average standard of living (the limitations of which are well known), rather than actual individual income levels. Furthermore we were limited to using the price of a specific price category of cigarettes in each country, rather than the average price. The latter approach is likely to provide more representative trends.

\section{Developed/developing country differences in tobacco price trends are not clear cut}

In the tobacco control literature it is customary to distinguish between high income economies and low and middle income developing economies. ${ }^{13}$ There are good reasons for doing this. Firstly, the burden of disease and death attributable to tobacco is rapidly shifting from high income countries to low and middle income countries. ${ }^{1}$ Secondly, most high income countries have imposed strong tobacco control policies, while many low and middle income countries have not, with the result that cigarette companies are shifting their marketing focus to the developing world. Thirdly, tobacco consumption has been decreasing in high income countries, while it has been rising, and is expected to rise further, in low and middle income countries. ${ }^{1}$

However, if one considers trends in cigarette prices, and specifically cigarette affordability, there is no obvious distinction between high income countries and low and middle income countries. There is only slight evidence that cigarettes have, on average, become less affordable in high income countries, and more affordable in low and middle income countries; of the 70 countries investigated in this study, cigarettes have become less affordable in $61 \%(17 / 28)$ of high income countries and in $43 \%$ (18/42) of low and middle income countries.

There are too many exceptions in both high income and low and middle income countries to categorically state that cigarettes have become less affordable in high income countries and more affordable in low and middle income countries.

But why did cigarette consumption decrease in the high income countries, and not in the low and middle income countries? If changes in cigarette affordability do not explain the relative change in cigarette consumption, it follows that non-price factors must have played a stronger role in reducing cigarette consumption in high income countries vis-à-vis low and middle income countries. A large proportion of high income countries have adopted comprehensive tobacco control strategies, consisting of advertising and sponsorship restrictions, health warnings, restrictions on smoking in public places, and restrictions on nicotine and tar content. These interventions, together with increasing excise taxes, form a powerful "package deal" to reduce smoking. This anti-tobacco "package deal" has turned societal norms against smoking in many high income countries, and, as a result, cigarette consumption has fallen.

\section{What this paper adds}

It is generally accepted that increases in cigarette prices is an extremely effective tool for tobacco control. If the price increases, cigarettes become less affordable. Recently a number of papers in Tobacco Control have explicitly investigated the affordability of cigarettes, focusing primarily on high income countries.

This paper considers a much larger sample of countries, and places a much stronger focus on developing countries. Also, this paper considers the relation between cigarette affordability and cigarette consumption, and estimates the "affordability elasticity of demand", based on cross sectional data.

On the other hand, cigarette smoking is often regarded as socially acceptable and even laudable in many low and middle income countries. The combination of weak or nonexistent tobacco control legislation and the active marketing activities of tobacco companies have increased cigarette consumption, despite the fact that cigarettes are relatively expensive and less affordable in most low and middle income countries. Also, given that per capita consumption of cigarettes in many low and middle income countries is still low compared to high income countries, the growth potential has been recognised by the multinational tobacco industry. In many low and middle income countries, the tobacco industry has been very successful in exploiting the market.

\section{Conclusion}

Despite the fact that cigarettes are taxed at much lower rates ${ }^{1}$ and are much cheaper in absolute terms, this paper has shown clearly that cigarettes are much less affordable in low and middle income countries, compared to high income countries. In countries with limited resources, the opportunity cost of tobacco consumption on households is particularly pronounced. ${ }^{18}$ Tobacco control advocates in developing countries should bring this to their governments' attention. This was done in Bangladesh with very good tobacco control consequences. ${ }^{19}$

Cigarettes have become more affordable in more than half the low and middle income countries analysed in this paper. As a first step in an effective tobacco control strategy, governments should impose sufficient excise tax increases to ensure that cigarettes are not becoming more affordable. Secondly, governments can create a social milieu where smoking is no longer perceived as socially desirable. The best way to do this is through legislation banning tobacco advertising and sponsorship, and restricting smoking in public areas.

The tide against tobacco has turned in most developed countries. Some low and middle income countries, such as South Africa, Thailand and Poland, have achieved much success by implementing strong tobacco control measures. Effective tobacco control is not the monopoly of high income countries; through comprehensive and watertight strategies, it is within the reach of low and middle income countries as well.

\section{ACKNOWLEDGEMENTS}

We thank Angela McClean and the Economist Intelligence Unit, London, for providing the price data.

\section{Authors' affiliations}

E H Blecher, C P van Walbeek, School of Economics, University of Cape Town, Cape Town, South Africa 


\section{REFERENCES}

1 The World Bank. Curbing the epidemic and the economics of tobacco control. Series: Development in practice. Washington DC: The World Bank, 1999.

2 Chaloupka FJ, Warner KE. The economics of smoking. National Bureau of Economic Research 1999:7047.

3 Jha P, Chaloupka FJ, eds. Tobacco control in developing countries. New York: Oxford University Press, 2000.

4 In: Abedian I, Van der Merwe R, Wilkins N, Jha P, eds. The economics of tobacco control: towards an optimal policy mix. Cape Town: Applied Fiscal Research Centre, University of Cape Town, 1998.

5 The World Bank. World development report 2002/2003. New York: Oxford University Press, 2003.

6 Shafey O, Dolwick S, Guindon GE, eds. Tobacco control country profiles, 2nd ed. Atlanta: American Cancer Society, WHO and UICC, 2003.

7 Scollo M. The Big Mac index of cigarette affordability. Tobacco Control 1996:5:69.

8 Lal A, Scollo M. Big Mac index of cigarette affordability. Tobacco Control 2002;11:280-2.

9 Ong LL. Burgernomics: The economics of the Big Mac standard. Journal of International Money and Finance 1997; 16:865-78.

10 Anon. Big MacCurrencies. Economist 15 April, 1995:74.
11 Guindon GE, Tobin S, Yach D. Trends and affordability of cigarette prices: ample room for tax increases and related health gains. Tobacco Control 2002;11:35-43.

12 Union Bank of Switzerland. Prices and earnings around the globe, $2000 \mathrm{ed}$. Union Bank of Switzerland, 2000.

13 Economist Intelligence Unit. World Cost of Living Survey. Available by subscription at http://eiu.enumerate.com/asp/wcol_WCOLHome.asp.

14 The World Bank. World Development Indicators Online. Available by subscription at http://devdata.worldbank.org/dataonline.

15 Gujarati DN. Basic econometrics, 4th ed. Boston: McGraw-Hill, 2003.

16 United States Department of Labor. Consumer price index - all urban consumers. Washington DC: United States Department of Labor, Bureau of Labor Statistics, March, 2004.

17 Guindon GE, Perucic A, Boisclair D. Higher tobacco prices and taxes in SouthEast Asia: an effective tool to reduce tobacco use, save lives and generate revenue, Health, Nutrition and Population Discussion Paper, World Bank's Human Development Network, October, 2003.

18 Efroymson D, Ahmed S, Townsend J, et al. Hungry for tobacco: an analysis of the economic impact of tobacco consumption on the poor in Bangladesh. Tobacco Control 2001; 10:212-7.

19 De Beyer J, Waverley Brigden L, eds. Tobacco control policy: strategies, successes and setbacks. Washington DC and Ottawa: The World Bank and the International Development Research Centre, 2003.

\section{The Lighter Side}

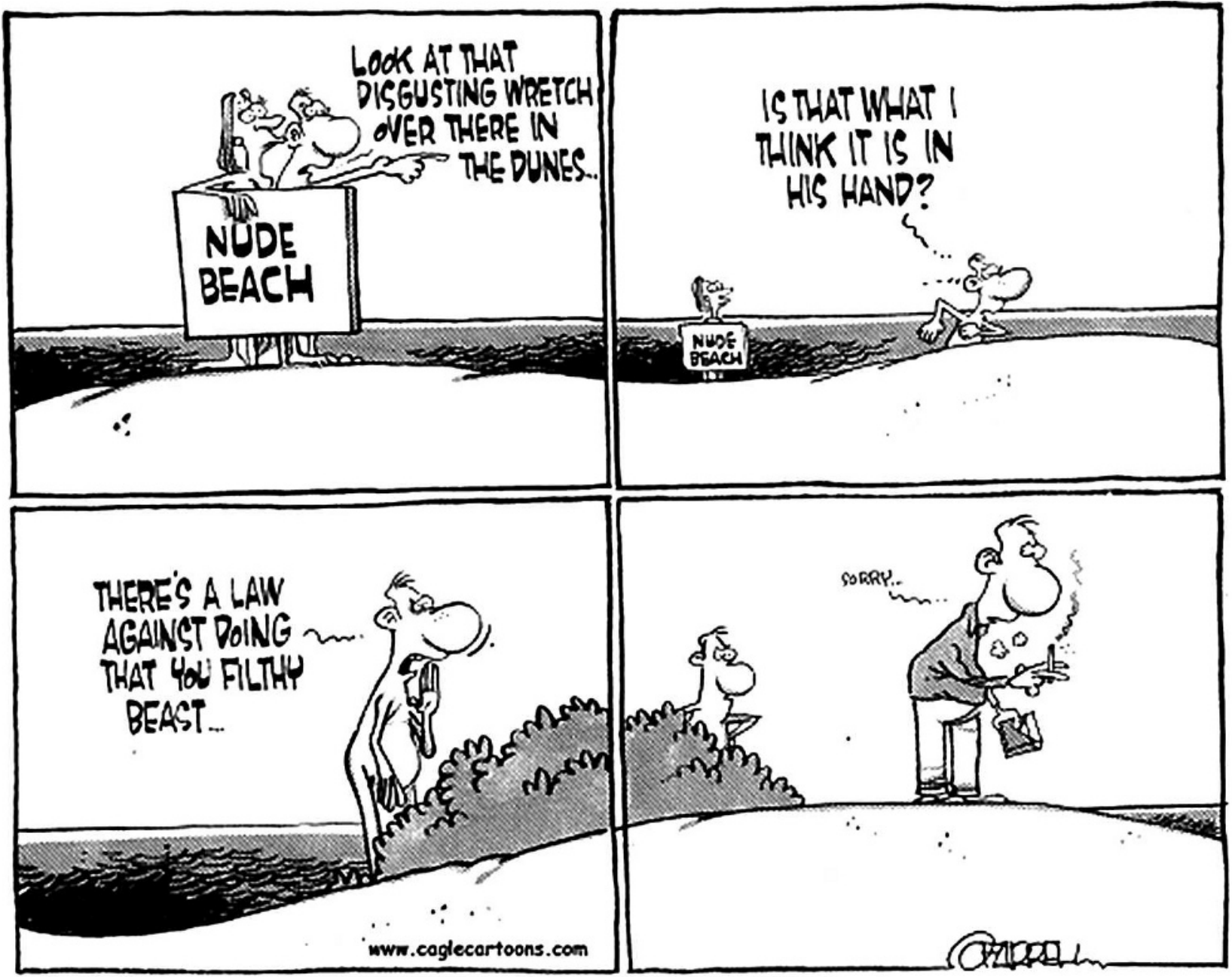

(c) 2004 Vince O'Farrell All rights reserved. 